\title{
Strain localization during tensile Hopkinson bar testing of commercially pure titanium and Ti6Al4V titanium alloy
}

\author{
Wojciech Moćko ${ }^{1, a}$, Leopold Kruszka ${ }^{2}$, and Adam Brodecki ${ }^{1}$ \\ ${ }^{1}$ Motor Transport Institute, 80, Jagiellońska st., 03-301 Warsaw, Poland \\ ${ }^{2}$ Gen. Jaroslaw Dabrowski Military University of Technology, 2, Gen. Sylwester Kaliski st., 00-908 Warsaw, Poland
}

\begin{abstract}
The goal of the analysis was to determine the strain localization for various specimen shapes (type A and type B according to PN-EN ISO 26203-1 standard) and different loading conditions, i.e. quasi- static and dynamic. Commercially pure titanium (Grade 2) and titanium alloy Ti6Al4V (Grade 5) were selected for the tests. Tensile loadings were applied out using servo-hydraulic testing machine and tensile Hopkinson bar with pre-tension. The results were recorded using ARAMIS system cameras and fast camera Phantom V1210, respectively at quasi-static and dynamic loading conditions. Further, specimens outline was determined on the basis of video data using TEMA MOTION software. The strain distribution on the specimen surface was estimated using digital image correlation method. The larger radius present in the specimen of type B in comparison to specimen of type A, results in slight increase of the elongation for commercially pure titanium at both quasi-static and dynamic loading conditions. However this effect disappears for Ti6Al4V alloy. The increase of the elongation corresponds to the stronger necking effect. Material softening due to increase of temperature induced by plastic work was observed at dynamic loading conditions. Moreover lower elongation at fracture point was found at high strain rates for both materials.
\end{abstract}

\section{Introduction}

A normalized specimens are usually applied for the determining of mechanical properties of titanium and its alloys using tensile Hopkinson bar. The small ratio between length and width of specimen (in comparison to typical tensile tests at quasi-static loading conditions) together with limited work hardening leads to necking at low strain values. As a consequence determination of the true stress-strain curve is complicated. Nonhomogeneous deformation of the specimens may be determined using digital speckle photography to obtain in-plane pointwise displacement and strain field [1]. Subsequently, results of strain distribution measurement were used to develop methodology based on inverse modelling for estimating visco-plastic material parameters at high strain rate conditions. Test were carried out using Hopkinson bar under compressive loading conditions for a mild steel. Necking process was also investigated using digital image correlation method during tensile tests of dual phase steel $[2,3]$. It was found that strain localization started even before the maximum load was attained in the specimen. An elasto-viscoplastic constitutive model was used to predict the observed stress-strain behaviour and strain localization. A good agreement between FEM simulation and DIC result was obtained. Wide range of tensile tests for a set of advanced high strength steels was carried out by Sato $[4,5]$. Analysis were performed at wide range of strain rates using a newly developed strain analysis system.

Digital image correlation method was also applied in order to study polymeric foam under impact loading using large diameter nylon Hopkinson bar [6]. Application of

\footnotetext{
${ }^{a}$ Corresponding author: wojciech.mocko@its . waw .pl
}

optical field measurement methods enables to determine non-homogenous strain and stress field. Similarly, fast camera videos recorded during Hopkinson bar tests of carbon-epoxy composites were used to analyse deformation mechanisms under high strain rate deformation regime [7]. Strain rate effect on modulus, yield, ultimate strength, strain to failure and on the in-plane shear properties was studied. Results of tensile tests obtained using digital image correlation method may be used to determine stressstrain curve including post-necking strain [8]. Hourglass type specimens were used for tensile tests, and the stressstrain curves were identified through an iteration process using finite element analysis. The strain at the position of minimum diameter was measured by DIC method.

Hopkinson bar test are carried out under compressive, shear and tensile loading conditions. Combined experimental-numerical approach was applied to extract the strain rate and temperature dependent mechanical behaviour from high strain rate experiments. The method [9-11] involves the identification of the material model parameters used for the finite element simulation. The technique was applied to determine stress-strain behaviour of Ti6Al4V titanium alloy using both high strain rate in-plane shear and tensile tests.

Fracture initiation is also studied using optical field measurement systems. The tests including low, intermediate and high strain rate tensile experiments were carried out on flat smooth, notched and centralhole tensile specimens extracted from AHSS sheet. A split Hopkinson bar was used to perform the high strain rate tension experiments. Selected surface strains, as well as local displacements were measured using high speed photography in conjunction with planar digital image correlation [12]. 
Table 1. List of specimen used in experiments.

\begin{tabular}{|c|c|c|c|c|c|c|}
\hline Spec No. & Material & Shape & $\begin{array}{c}\text { Strain rate } \\
{\left[\mathrm{s}^{-1}\right]}\end{array}$ & $\begin{array}{c}\text { Yield point } \\
{[\mathrm{MPa}]}\end{array}$ & $\begin{array}{c}\text { Tensile strength } \\
{[\mathrm{MPa}]}\end{array}$ & Elongation \\
\hline 3 & Grade 2 & type A & $1.0 \times 10^{-2}$ & 470 & 510 & 0.42 \\
\hline 4 & Grade 2 & type A & $1.0 \times 10^{-2}$ & 480 & 517 & 0.42 \\
\hline 9 & Grade 2 & type B & $1.0 \times 10^{-2}$ & 478 & 514 & 0.43 \\
\hline 10 & Grade 2 & type B & $1.0 \times 10^{-2}$ & 476 & 518 & 0.44 \\
\hline 11 & Grade 2 & type A & $5.8 \times 10^{2}$ & 623 & 610 & 0.29 \\
\hline 12 & Grade 2 & type A & $5.8 \times 10^{2}$ & 628 & 618 & 0.29 \\
\hline 13 & Grade 2 & type B & $6.0 \times 10^{2}$ & 612 & 606 & 0.30 \\
\hline 14 & Grade 2 & type B & $6.2 \times 10^{2}$ & 626 & 615 & 0.32 \\
\hline 17 & Grade 5 & type A & $1.0 \times 10^{-2}$ & 1003 & 1035 & 0.26 \\
\hline 18 & Grade 5 & type A & $1.0 \times 10^{-2}$ & 1007 & 1038 & 0.26 \\
\hline 23 & Grade 5 & type B & $1.0 \times 10^{-2}$ & 1007 & 1043 & 0.26 \\
\hline 24 & Grade 5 & type B & $1.0 \times 10^{-2}$ & 1017 & 1045 & 0.26 \\
\hline 25 & Grade 5 & type A & $4.5 \times 10^{2}$ & 1115 & 1086 & 0.19 \\
\hline 26 & Grade 5 & type A & $5.0 \times 10^{2}$ & 1115 & 1094 & 0.19 \\
\hline 27 & Grade 5 & type B & $4.5 \times 10^{2}$ & 1113 & 1092 & 0.19 \\
\hline 28 & Grade 5 & type B & $4.5 \times 10^{2}$ & 1126 & 1107 & 0.21 \\
\hline
\end{tabular}

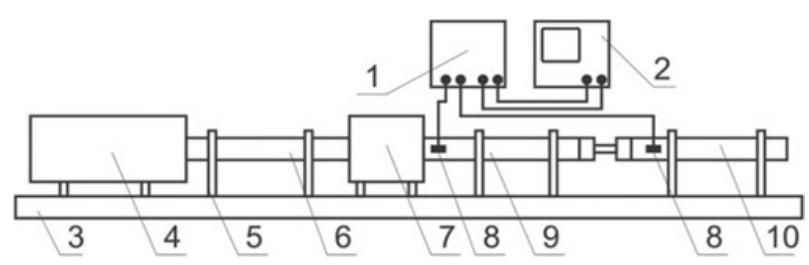

Figure 1. Scheme of the tensile Hopkinson bar with pre-tension. 1 - Wheatston's bridge, 2 - digital oscilloscope, 3 - base, 4 pre-strain hydraulic actuator, 5 - support, 6 - pre-strained part of incident bar, 7 - hydraulic clamp, 8 - tensometers, 9 - free part of incident bar, 10 - transmitter bar.

This paper presents analysis of the necking phenomenon during quasi-static and dynamic tensile tests of commercially pure titanium (CPT) and Ti6Al4V titanium alloy. Application of digital image correlation method enables to investigate differences between low and high strain rate deformation of those materials.

\section{Experimental method}

\subsection{Specimens}

At both, quasi-static and dynamic deformation rates the specimens of type A according to standard PN-EN ISO 26203-1 were used. The length and width of gauge were equal to $7 \mathrm{~mm}$ and $4 \mathrm{~mm}$, respectively. The specimens were cut using electro discharge machining from the $3 \mathrm{~mm}$ thick sheet of commercially pure titanium (CPT) and TiAl6V4 titanium alloy. List of the specimens and loading parameters are shown in Table 1.

\subsection{Tensile test}

The tensile tests were carried out using the servo-hydraulic testing machine manufactured by Instron company and pre-tension Hopkinson bar $[13,14]$ at quasi-static and dynamic range of strain rates. The testing stand at Motor Transport Institute laboratory $[15,16]$ is equipped with the bars of $20 \mathrm{~mm}$ in diameter made of 7075-T6 aluminium alloy (Fig. 1). The incident bar of $3600 \mathrm{~mm}$ in length is divided into a pre-tension section with a length of $1600 \mathrm{~mm}$ and a free end. The clamp which confines the bar during initial loading with the use of a hydraulic actuator is placed between the pre-tension and free section of the incident bar. The transmission bar length is equal to $1800 \mathrm{~mm}$. The history of elastic wave in the bars is determined using tensometers, than amplified at the broad-band bridge and finally recorded by a digital oscilloscope.

\subsection{Digital image correlation system}

The test was recorded using Phantom V1210 fast camera at a resolution of $384 \times 128$ and frame rate equal to 150000 at dynamic range of loading. In order to obtain clear view without blurring of measurement grid required in DIC analysis the shutter time was set to $2 \mu$ s. Very short time of frame acquisition requires very strong lighting, therefore two COOLH illuminators emitting very focused light beam were applied. The arrangement including Hopkinson bar, fast camera and lighting system is presented in Fig. 2. At the quasi-static deformation rates ARAMIS 4M video system with resolution equal to $2400 \times 1728$ pixels was used. The videos recorded during experiments were subsequently analysed by DIC method implemented in the ARAMIS software to determine 2D field of displacement.

\section{Experimental results}

\subsection{Quasi-static and dynamic tensile curves}

Stress-strain curves of CPT and TiAl6V4 alloy are shown in Fig. 3 and Fig. 4 respectively. Small, but clearly to observe influence of the specimen shape on the elongation and necking at fracture point were found for CPT. The larger radius present in the specimen of type $\mathrm{B}$ in comparison to specimen of type A, results in slight increase of the elongation for both quasi-static and dynamic loading conditions. Influence of the specimen 


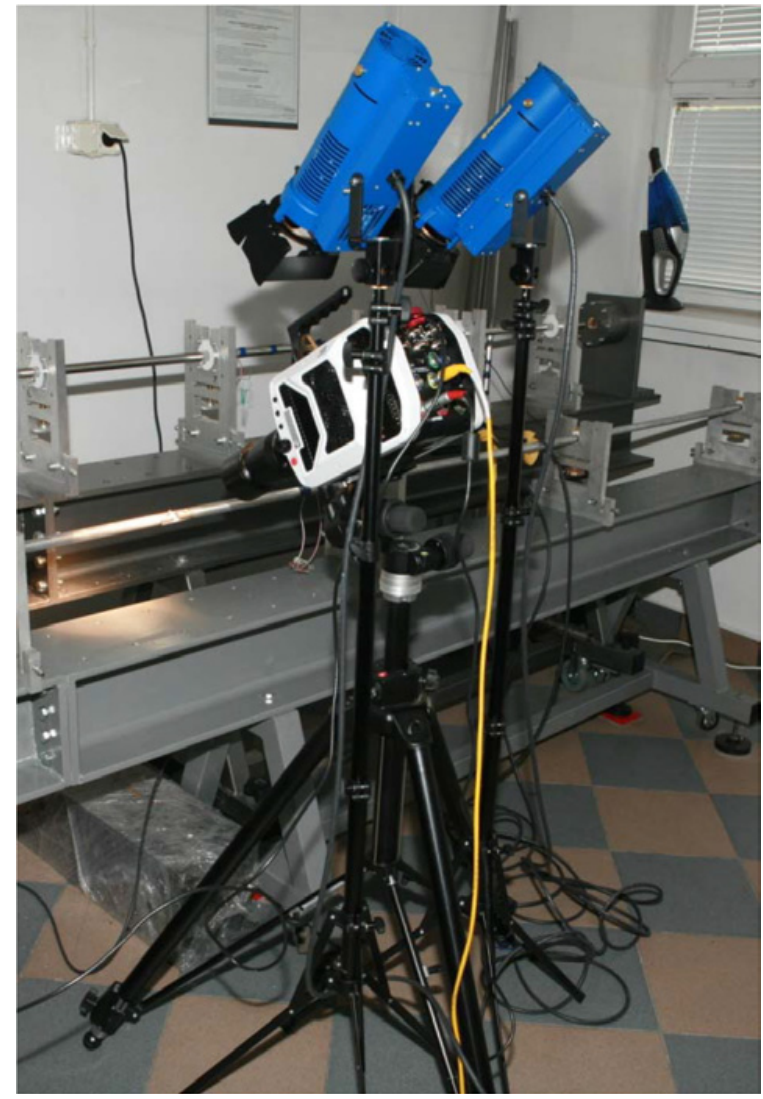

Figure 2. TSHPB stand with high speed camera.

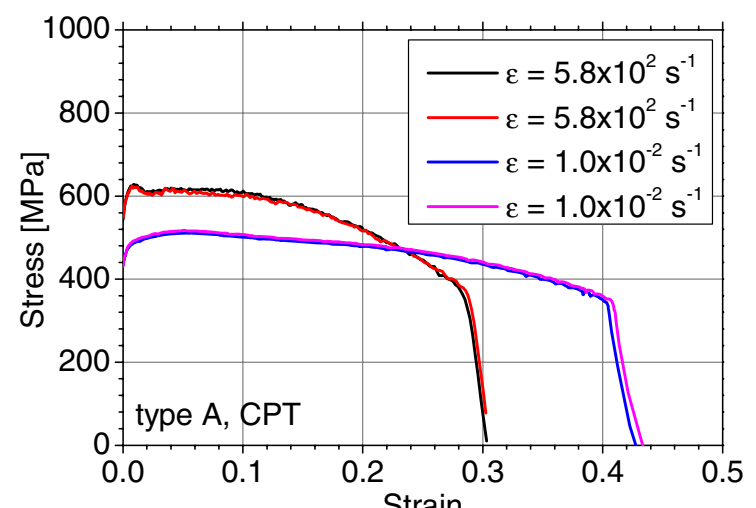

a)

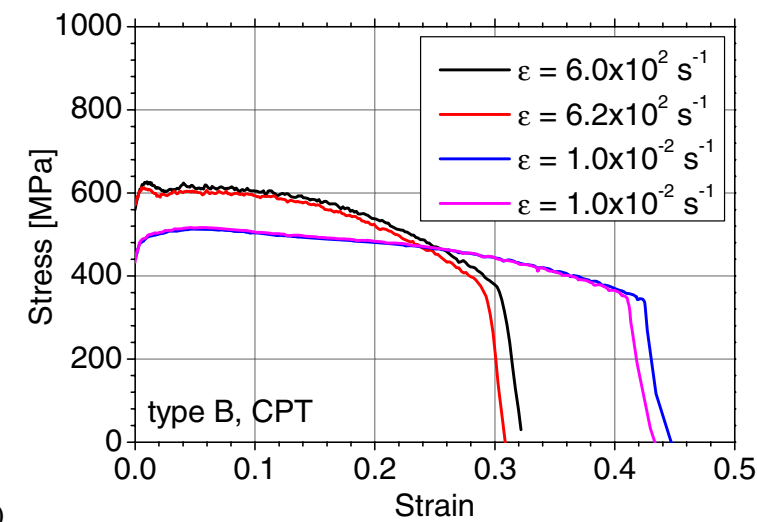

Figure 3. Engineering stress strain curves of $\mathrm{CPT}$ at various strain rates determined for specimen of type $\mathrm{A}$ a) and type $\mathrm{B}$ b).

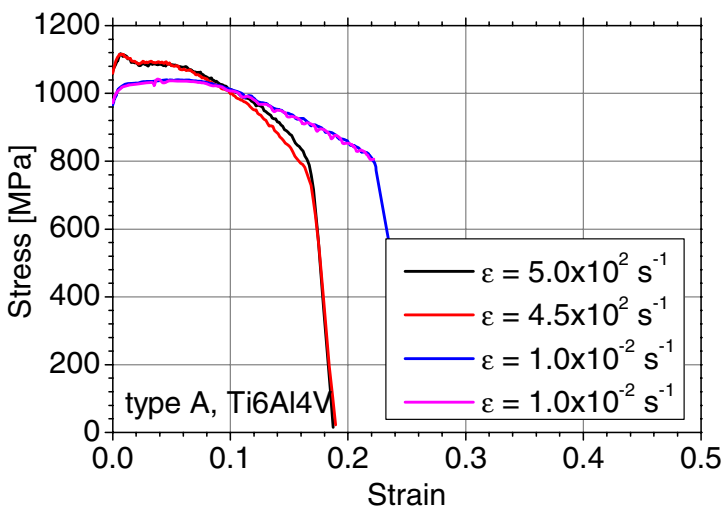

a)

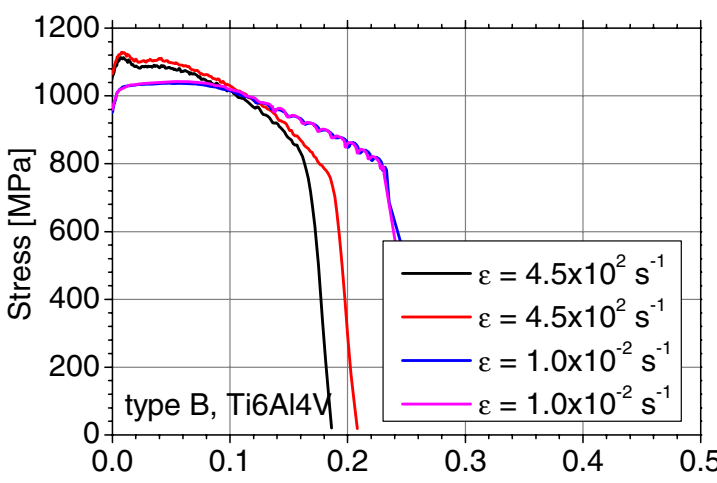

b)

Strain

Figure 4. Engineering stress strain curves of Ti6Al4V titanium alloy at various strain rates determined for specimen of type $\mathrm{A}$ a) and type B b).
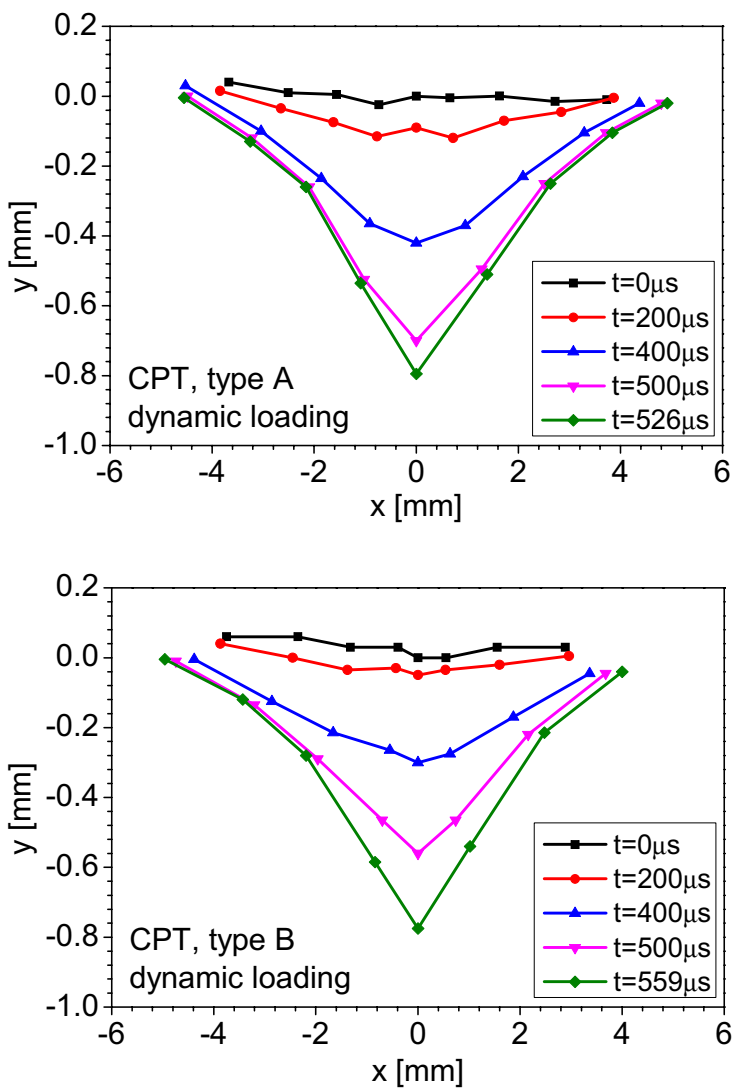

Figure 5. History of specimen outline during deformation of CPT for dynamic loading for specimen of type A a) and type B b). 


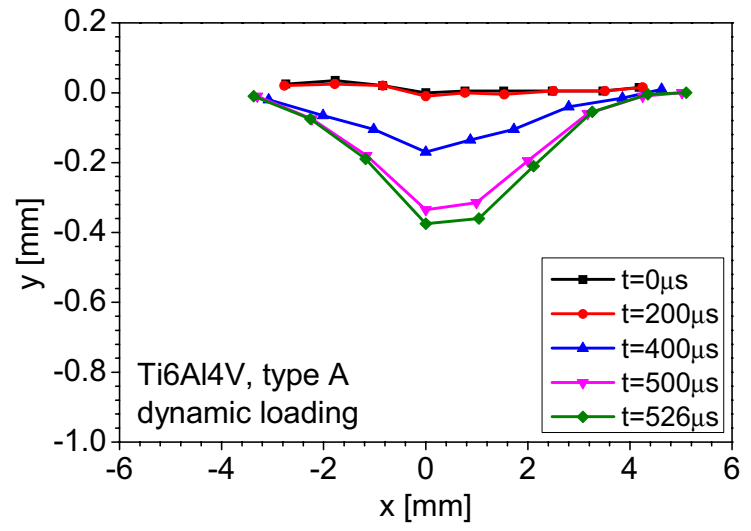

a)

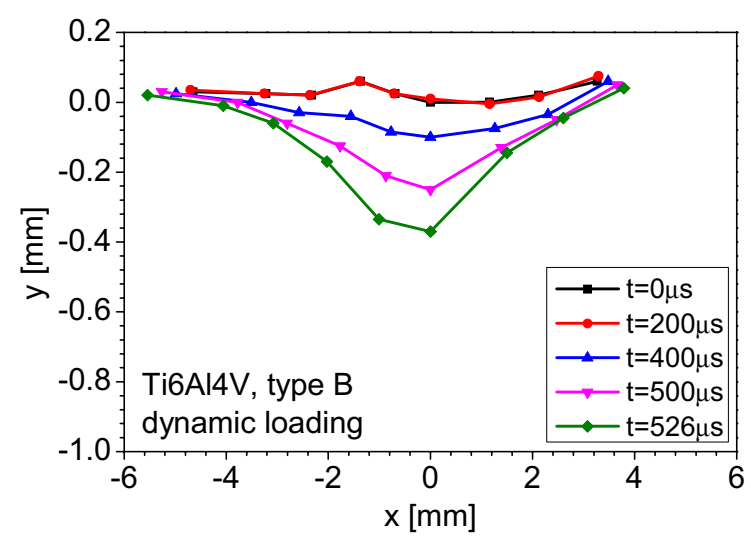

Figure 6. History of specimen outline during deformation of Ti614V titanium alloy for dynamic loading for specimen of type A a) and type B b).

shape on elongation for TiAl6V4 may be neglected. The increase of the elongation corresponds to the stronger necking effect (if the necking is stronger the width of specimen in the necking point is lower). Exact elongation values are shown in Table 1 .

The influence of the strain rate on the tensile curve is clear to observe. Both materials shows strain rate hardening effect. Yield stress at dynamic loading condition is about $100 \mathrm{MPa}$ higher than for quasi-static loading conditions. Material softening due to increase of temperature induced by plastic work was observed at dynamic loading conditions. Moreover lower elongation at fracture point was found at high strain rates for both materials. This behaviour may be related to temperature increase and plastic deformation mechanisms as well.

\subsection{Evolution of specimen thickness at necking point}

Evolution of the specimen outline during tensile tests was determined at dynamic loading conditions using TEMA MOTION software on the basis of recorded videos. The charts shows average value determined on the basis of measurement of both edges of specimen. The change of specimen shape at subsequent step of deformation is show in Fig. 5 and Fig. 6 for CPT and TiAl6V4 alloy respectively. It may be observed that necking effect is stronger for the CPT independently on the shape of

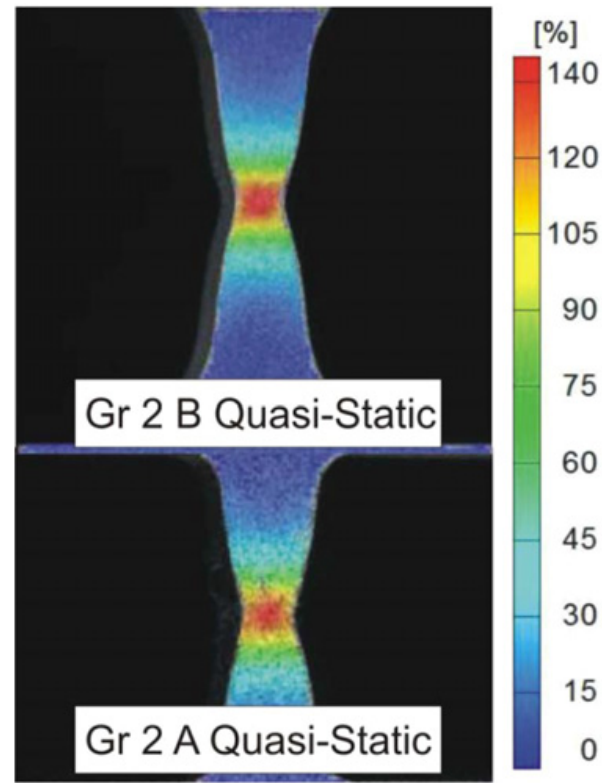

Figure 7. Strain distribution determined during quasi-static tensile test of CPT.

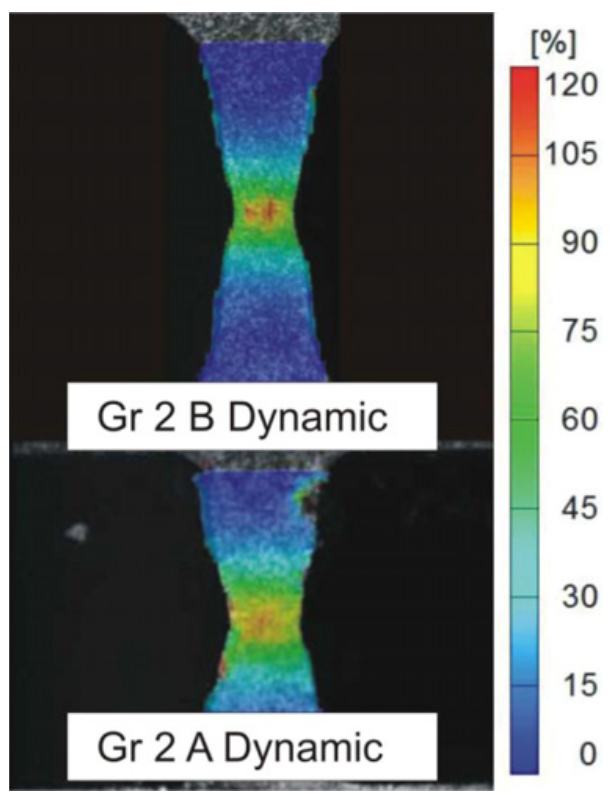

Figure 8. Strain distribution determined dynamic tensile test of CPT.

specimen. Moreover it may be found that for the specimens of shape of type A for both materials necking grows quicker than for the type B. Value of reduction of the specimen width at necking point is equal $0.8 \mathrm{~mm}$ and $0.4 \mathrm{~mm}$ for the CPT and TiAl6V4 alloy respectively.

\subsection{Strain distribution at specimen surface}

Results of analysis conducted with the use of digital correlation method are shown in Figs. 7-9. Presented frames were taken form videos just before macroscopically observed fracture. In all cases strain localization is ease to observe. It is located in the middle of gauge. The strain 


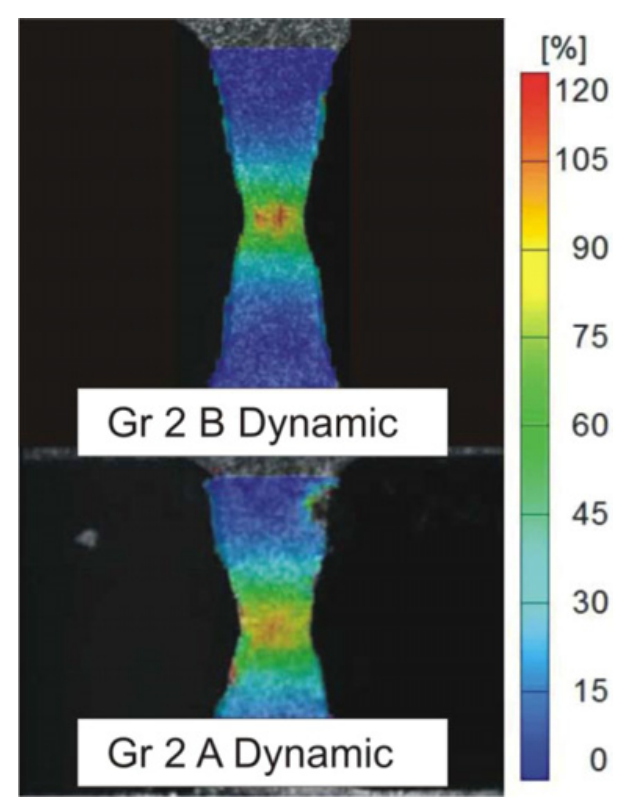

Figure 9. Strain distribution determined quasi-static test of Ti6Al4V alloy.

field is not uniform across specimen with. It may be found that strain value at necking region is highest near specimen longitudinal axis. Comparison between quasi-static and dynamic deformation mechanism of CPT is presented in Fig. 7 and Fig. 8 respectively. Maximum values of strain determined locally using DIC method are strongly dependent on strain rate. Local strain before fracture is equal to 1.4 (Fig. 7) at static loading conditions and equal to 1.0 (Fig. 8) at dynamic loadings. It may be stated that locally observed behaviour is in coincidence with macroscopically determined strain. Strain estimated using Hopkinson bar methodology was equal to 0.3 whereas strain measured with extensometer during quasi-static tensile test was equal to 0.42 . Taking into account both method of strain determining (local and macroscopic) it may be found that elongation at quasi-static loading conditions is $330 \%$ higher in comparison to the dynamic one.

Locally observed strain of Ti6Al4V is equal to 0.6 at quasi-static loading conditions whereas macroscopically observed strain is equal to 0.25 . It means that local strain is $240 \%$ higher than macroscopically determined one. It may be stated that necking phenomenon is stronger for the CPT than for Ti6Al4V alloy.

\section{Summary}

Tensile tests carried out using Hopkinson bar with pre-tension were recorded using high speed camera. Subsequently, the videos were analysed using digital image correlation method. On the basis of determined strain distribution, it was found that locally observed strain is $330 \%$ and $240 \%$ higher than macroscopic one, respectively, for the CPT and Ti6Al4V alloy. Moreover, elongation value depends on strain rate. Locally determined strain at quasi-static tensile tests of CPT was equal to 1.4 , whereas at dynamic loading conditions was equal to 1.0. Macroscopic strain shows similar behaviour, i.e. strain was equal to 0.42 and 0.3 respectively at quasistatic and dynamic loading conditions.

This study was supported by the Polish National Centre for Research and Development (GRAF-TECH/NCBR/14/26/ 2013)

\section{References}

[1] J. Kajberg, B. Wikman, Viscoplastic parameter estimation by high strain-rate experiments and inverse modelling - Speckle measurements and highspeed photography, Int. J. Solids Struct. 44, 145-164 (2007)

[2] V. Tarigopula, O.S. Hopperstad, M. Langseth, A.H. Clausen, F. Hild, A study of localisation in dualphase high-strength steels under dynamic loading using digital image correlation and FE analysis, Int. J. Solids Struct. 45, 601-619 (2008)

[3] J. Qin, R. Chen, X. Wen, Y. Lin, M. Liang, F. Lu, Mechanical behavior of dual-phase high-strength steel under high strain rate tensile loading, Mat. Sci. Eng. A-Struct. 586, 62-70 (2013)

[4] K. Sato, Q. Yu, J. Hiramoto, T. Urabe, A. Yoshitake, A method to investigate strain rate effects on necking and fracture behaviors of advanced high-strength steels using digital imaging strain analysis, Int. J. Impact Eng. 75, 11-26 (2015)

[5] W. Moćko, Comparison of energy absorption properties of high nitrogen austenitic steel and cast alloy determined using low velocity perforation test. Arch. Metall. Mater. 59, 65-69 (2014)

[6] J. Liu, D. Saletti, S. Pattofatto, H. Zhao, Impact testing of polymeric foam using Hopkinson bars and digital image analysis, Polym. Test. 36, 101-109 (2014)

[7] H. Koerber, J. Xavier, P.P. Camanho, High strain rate characterisation of unidirectional carbon-epoxy IM78552 in transverse compression and in-plane shear using digital image correlation, Mech. Mater. 42, 1004-1019 (2010)

[8] M. Kamaya, M. Kawakubo, A procedure for determining the true stress-strain curve over a large range of strains using digital image correlation and finite element analysis. Mech. Mater. 43, 243-253 (2011)

[9] J. Peirs, P. Verleysen, W. Van Paepegem, J. Degrieck, Determining the stressestrain behaviour at large strains from high strain rate tensile and shear experiments, Int. J. Impact Eng. 38, 406-415 (2011)

[10] W. Moćko, J. Janiszewski, M. Grązka, Application of an extended Rusinek-Klepaczko constitutive model to predict the mechanical behavior of 6082-T6 aluminum under Taylor impact test conditions. J Strain Analysis 48, 364-375 (2013)

[11] W. Moćko, J. Janiszewski, J. Radziejewska, M. Grązka, Analysis of deformation history and damage initiation for 6082-T6 aluminium alloy loaded at 
classic and symmetric Taylor impact test conditions. Int. J. Impact Eng. 75, 203-213 (2015)

[12] C. C. Roth, D. Mohr, Effect of strain rate on ductile fracture initiation in advanced high strength steel sheets: Experiments and modeling. Int. J. Plasticity 56, 19-44 (2014)

[13] G.H. Staab, A. Gilat, A Direct Tension SHB for high strain rate testing, Exp. Mech. 31, 232-235 (1991)

[14] H. Kolsky, An Investigation of the mechanical properties of materials at very hign rates of deformation of loading. Proc. Phys. Soc. 62B, 647-700 (1949)
[15] W. Moćko, Analysis of the impact of the frequency range of the tensometer bridge and projectile geometry on the results of the measurement by the split Hopkinson pressure bar method. Metrol. Meas. Syst. 20, 555-564 (2013)

[16] W. Moćko, J.A. Rodríguez-Martínez, Z.L. Kowalewski, A. Rusinek, Compressive viscoplastic response of 6082-T6 and 7075-T6 aluminium alloys under wide range of strain rate at room temperature: Experiments and modelling. Strain 48, 498-509 (2012) 